\title{
A perspective on the impact of reproductive technologies on food production in Africa
}

\author{
Esté van Marle-Köster \& Edward C Webb \\ Department of Animal and Wildlife Sciences, University of Pretoria, Private bag X20, Hatfield South Africa \\ Corresponding authors: Evm.koster@up.ac.za; $\underline{\text { Edward.webb@up.ac.za }}$
}

\begin{abstract}
Africa for the largest part is still regarded as part of the developing world and has a history of political instability, natural disasters, floods and droughts that all had an effect on the development of livestock production systems and the potential application of biotechnologies. It is expected that the human population in sub Saharan Africa will experience a growth of $1.2 \%$ per year over the next 30 years. There is therefore pressure to increase sustainable productivity of livestock. Reproductive technologies such as Artificial Insemination in Africa were driven primarily by the need to control or prevent venereal diseases like Trichomoniases and Campylobacter fetus venerealis in cattle. Reproductive biotechnology had a limited impact in Africa due to several factors including a lack of infrastructure and animal recording systems, clear breeding objectives and continuously changing production systems and markets. Africa has a large variety of genetic resources adapted to the diverse environment and production systems and biotechnology should be applied within this context for an increase in food production.
\end{abstract}

Key words: Reproductive biotechnology, Artificial insemination, Embryo transfer, Indigenous, cattle sheep, goats, Animal recording, Animal identification, adaptation

\section{Introduction}

Africa is the second largest continent in the world with an estimated population size of approximately one billion people. This continent boasts a range of diverse climatic regions including desert, semi-deserts 
regions, tropical rain forests and some of the most beautiful open savannas in the world. African people have always been dependant on some form of agriculture for their livelihood and through many centuries of discovery, colonization and independence, livestock has been kept under a range of production systems. Africa for the most part is still regarded as part of the developing world and has a history of political instability, natural disasters, floods and droughts that all had an adverse effect on the development of livestock production systems and potential application of new technologies. Traditional livestock systems have always favoured cattle, sheep and goats as the major species and each contributed to the needs of the household in different ways. Cattle are very much associated with status in the community and serves as an indication of prosperity, while sheep and goats are also used in rituals, cultural ceremonies and for consumption. Poultry is kept by most households for eggs and meat and is a major contributor of animal protein in deep rural areas. Swine are less popular due to religious reasons, as well as the intensive nature of production system and more complex feed requirements (Faustin et al. 2003).

The world population is expected to grow to an estimated 9.5 billion people by 2050 and most of the growth will occur in the developing world (Thornton, 2010). It is expected that the human population in sub Saharan Africa will experience a growth of $1.2 \%$ per year. Projected trends for meat and milk consumption in the developing world by 2015 are $32 \mathrm{~kg}$ and $55 \mathrm{~kg}$ respectively, while current per capita consumption is approximately $28 \mathrm{~kg}$ of meat and $44 \mathrm{~kg}$ of milk per year. These trends indicate an ever increasing demand for protein and it is expected that this protein will be supplied by livestock (Delgado et al. 1999; Kahi \& Rewe, 2008; Pica-Ciamarra et al. 2010).

There is therefore pressure to increase the productivity of livestock production for both dairy and meat from the respective species on a commercial level. This increase in productivity and efficiency will have to take into account the improvement of sustainability of livestock production in Africa (Cunningham, 1999; Sholtz et al 2011). Due consideration is required for reduction of livestock emissions under natural grazing systems and welfare issues with regard to the technologies employed (Koehler-Rollefson, 2012). 
This increase in productivity has to take place in environments subjected to more frequent droughts, with limited available pastures for grazing and high costs of intensive feeding. In the developed world biotechnology has been adopted on several levels for increasing productivity and lowering production costs by selection and genetic improvement in most livestock species (Van Arendonk, 2011). Biotechnology has found application not only in reproduction and genetics, but also in improvements in health (Ruxandra, 2010) and nutrition (Rode et al. 2010). Several papers have been published on the potential impact of biotechnology in African livestock production (Kahi \& Rewe, 2008; Rege et al. 2011). It is clear that the implementation of biotechnology, including reproductive technology has been complex with varying degrees of success in different African countries. In this chapter reproductive technologies and its associated effect on genetic improvement have been reviewed in context with the livestock production systems used in Africa with a perspective on the potential impact on food production.

\section{Livestock breeds in Africa}

Africa has a large number of different local cattle, sheep and goat breeds and a number of exotic breeds that have been introduced to several countries over the past few centuries. Several surveys have been conducted to determine population sizes and breed trends but the statistics remain inadequate. Statistics on population sizes and different breeds reported by Scherf (2000) indicated that in Africa there are 251 cattle, 147 sheep and 89 goat breeds and from these 23 and 8 cattle and sheep breeds respectively are already extinct. In Table 1 the top 15 countries in Africa are shown with the most cattle, sheep and goats as provided by the FAO STAT (2012) and there is no doubt that these species have a major role to play in African agriculture. The focus for genetic improvement should be on these species and appropriate biotechnology and genetic tools should be employed to ensure success under diverse and challenging systems. 
Table 1 Estimated population sizes for cattle, sheep and goats sub Saharan Africa (FAOSTAT, 2012) http://faostat3.fao.org/home/index.html)

\begin{tabular}{lrrr}
\hline Country & Cattle & Goats & Sheep \\
\hline Algeria & 1650000 & 3800000 & 20000000 \\
Angola & 5143000 & 2571000 & 355000 \\
Burkina Faso & 9845000 & 12377500 & 8050000 \\
Cameroon & 5700000 & 4450000 & 3850000 \\
Central African Republic & 3893000 & 4862000 & 388000 \\
Chad & 7419100 & 6751300 & 3026500 \\
Egypt & 4524950 & 4200000 & 5591580 \\
Ethiopia & $\mathbf{5 0 8 4 0 0 0}$ & 21960700 & 25979900 \\
Kenya & 17862900 & 13291700 & 9899300 \\
Libya & 195000 & 2700000 & 7000000 \\
Madagascar & 9900000 & 1280000 & 730000 \\
Mali & 9163280 & 16522500 & 11865300 \\
Mauritania & 1677630 & 5500000 & 8860000 \\
Morocco & 2895800 & 5685700 & 18023200 \\
Niger & 9817340 & 13673100 & 10917200 \\
Nigeria & 16578000 & $\mathbf{5 6 5 2 4 1 0 0}$ & 35519800 \\
Somalia & 5350000 & 12700000 & 13100000 \\
South Africa & 13731000 & 6274850 & 24501000 \\
Sudan & 41726700 & 43441000 & $\mathbf{5 2 0 1 4 1 0 0}$ \\
Tunisia & 670900 & 1295940 & 7234070 \\
Uganda & 7650000 & 8800000 & 1850000 \\
United Republic of & 19500000 & 12900000 & 4200000 \\
Tanzania & & &
\end{tabular}

Since the late 1990's there has been awareness regarding conservation of farm animal genetic resources and several surveys and studies have followed on livestock breeds in Africa (Rege, 1999). Studies were aimed to define breeds on common ancestry as livestock breeds were often "named" according to the geographical or ecological region where they were kept. Phenotypic and genetic characterization of a large number of African livestock breeds has been conducted that contributes to the knowledge and utilization of these breeds in the different countries. Phenotypic characterization, include studies based on performance and body measurements and type/breed traits (Mwacharo et al. 2006; Amare et al. 2012). Since the development of molecular techniques and DNA marker discoveries, most studies after the 1990's have focused on genetic diversity and population structure of the various indigenous and local 
breeds (Hanotte \& Jianlin, 2005; Lenstra et al. 2011). Studies such as these have provided valuable insight to the dangers of uncontrolled cross breeding and decrease of effective population sizes for some of these breeds for example the studies by Ibeagha-Awemu \& Erhardt (2004) on12 African cattle breeds, Gizaw, et al. (2007) on indigenous sheep in Ethiopia and Qwabe et al. (2012) on Namakwa Afrikaner sheep in South Africa.

Livestock breeds in Africa have evolved over many centuries in different regions that are characterized by large seasonal variations that affected the available quantity and quality of the grazing and the ecto- and endo parasite infestations. Production systems vary from smallholders with small herd or flock sizes to pastoralists that need to migrate on a seasonal basis and require different species and breeds to cope within these systems (Mirkena et al 2010). Most of these local African breeds however are associated with lower reproduction and growth compared to exotic breeds. There are however sufficient evidence and examples for a number of African breeds that have unique characteristics with regard to adaptations to heat and disease susceptibility (Bonsma, 1980). Cattle breeds such as the Ndama has resistance against tryponosomasis (Roberts \& Gray, 1973; Mattioli et al. 2000) and Sanga breeds such as the Nguni of South Africa has been shown to be more adapted to subtropical areas with high temperature, humidity and feeding requirements and tick resistance (Spickett et al. 1989; Mapiye et al. 2007). Research as indicated that sheep breeds such as the Red Maasai has a higher resistance against endoparasites compared to Dorper sheep (Barker, 1998), while West African Djallanke sheep showed resistance against tryponosomasis and endoparasite infections (Goosens, 1999).

Due to the poorer production potential of local breed types compared to exotics breeds, there have been several attempts to select for increased growth and higher outputs in these breeds. Reproductive biotechnologies were applied with the aim to genetically improve the breeds and enhance production. Local breeds were crossed with exotic breeds, but the outcomes were often disappointing due to the lack of defining breeding objectives and appropriate selection criteria (Van Arendonk et al. 2011). 
Crossbreeding further has the danger of decreasing adaptability to both the specific climatic conditions and the type of production system that these breeds have become adapted to (Taberlet et al. 2008). The use of and impact of reproductive technologies to improve the genetic potential and increase food production in Africa should therefore be evaluated by keeping these factors in mind.

\section{Reproductive biotechnologies}

Reproductive biotechnologies are employed for a variety of purposes in different species and these technologies are used world-wide. Reproductive technologies such as AI have the potential to increase genetic gain through the use of superior and proven sires. Through AI there is selection pressure on certain traits that need to be improved and this can be effectively done via sires with large numbers of offspring. The semen of a proven bull can be used to sire thousands of calves while the bull can only sire about 30 calves per natural mating in a breeding season. In addition, the expenses associated with the transportation of animals for breeding purposes as well as the constraints associated with the quarantine of animals, no longer limits the use of the best genetic material worldwide. AI has the advantages of importation of semen of the elite sires and used in local breeds, where a structured seed stock industry do not exist for example in some African countries. It also holds the advantage for use in small herds where farmers cannot afford to keep seed stock bulls and do not need to maintain a bull. Farmers can use different AI bulls in their programs to satisfy the breeding objective of the enterprise.

The initial commercialization of artificial insemination (AI) of livestock as reproductive biotechnology in Africa was driven primarily by the need to control or prevent venereal diseases like Trichomoniases and Campylobacter fetus (previously known as Vibriosis) in cattle. The real potential of AI only became apparent after the development of the recto-vaginal AI technique and dilution, processing and cryopreservation of bull semen in easily transportable liquid nitrogen (Dewar) flasks. The use of frozen and stored germplasm also has benefits in terms of the conservation of genetic resources and a number of scarce species already benefit from this technology (Holt \& Pickard, 1999). 
Many scarce African mammals are deserving of conservation efforts, but the reproduction of only a few of these have been studied in sufficient detail to warrant the successful application of reproductive biotechnologies as conservation tool. Generally the use of in vitro fertilization and embryo transfer in wildlife has been limited to date (Holt \& Pickard, 1999). In South Africa these technologies have been used to breed disease-free buffalo (free from foot and mouth disease and tuberculosis) and other scarce African ungulates like Roan and Sable antelope, due to the increasing monetary value of these species for the game and hunting industry.

Other reproductive biotechnologies that are used include the synchronization of estrus in female livestock to improve the practical management of AI within breeding programs. Synchronization of estrus makes it possible to artificially inseminate a large number of females on a predetermined date, which eliminates the necessity of daily estrus observations, followed by artificial insemination. The use of synchronization of estrus as management strategy in breeding programs has resulted in conception rates that are comparable to natural mating. The use of AI in extensive production systems in South Africa has yielded mixed results - estrus observation (heat detection) has been identified as the single most important factor that detracts from breeding success in such systems.

AI is beneficial when the genetic merit of the male is high, but the genetic contribution of sought after females in a herd can be increased by means of embryo transfer (ET) to recipient females (surrogate mothers). This technology has also been employed in a number of livestock species and wildlife on the African continent. The use of multiple ovulation and embryo transfer (MOET) has become an accepted practice in the breeding of stud cattle, sheep, goats and some wild ungulates. The success rates has not been exceedingly high (about 30\%) but the adoption of better embryo sorting methods and transfer of two embryos per recipient female, have increased the conception rates to above $50 \%$. 


\section{Impact of Artificial insemination}

It is widely agreed that $\mathrm{AI}$ of animals is the single most successful reproductive biotechnology ever employed for the genetic improvement of livestock, but the exact impact has been questioned. Thibier \& Wagner (2002) conducted a world survey of the artificial insemination industry and also estimated the impact of AI on different continents. The data shows that already in 1998 there was about 648 semen collection centres and 1635 semen banks worldwide. It is estimated that more than 40000 bulls were housed at semen collection centres and about 264 million doses of semen were produced per annum towards the end of the 1990's. The largest proportion of semen processed (>95\%) was frozen in liquid nitrogen and more than $75 \%$ of the semen dosses were from the Bos taurus-type dairy breeds.

Despite the technological developments and international acceptance of this reproductive biotechnology, Africa was relatively slow to adopt these biotechnologies. Africa produced less than $1 \%$ of the total number of semen doses in 1998, from about 650 bulls per annum, which represent about $1.57 \%$ of the global pool of bulls used for semen collection. Based on the data obtained by Thibier \& Wagner (2002), South Africa was the most active semen producing country in 1998. Breeds of bulls used for semen collection purposes in Africa are summarized in Table 2.

Semen was initially stored in glass ampules which were kept at $-196^{\circ} \mathrm{C}$ in liquid nitrogen flasks, but plastic straws that contain between 0.25 to $0.5 \mathrm{ml}$ of diluted semen became more popular in South Africa towards the end of the 1970's. Other countries in Africa adopted the same technology and the storage of semen straws in liquid nitrogen flasks and use of frozen-thawed semen in AI programs were adopted almost over-night. Similarly, the initial artificial insemination technique (vaginal deposition) that required a speculum and light source to deposit semen in the antrum of the cervix was soon replaced with the recto-vaginal technique (also known as the cervical fixation).

The recto-vaginal AI-technique was adopted with relative ease by cattle managers and technicians in Africa, after completion of a short course in artificial insemination at tertiary institutions or AI- 
cooperatives. Most countries in Africa have rules and regulations in place to control the use of these reproductive biotechnologies, but the aims are to guard against the exploitation of genetic resources, rather than the biotechnologies per se. The adoption rate of artificial insemination of cattle and buffalo in Africa is estimated at about $1.68 \%$, compared to the world average of $20.32 \%$ (Thibier \& Wagner, 2002), which leaves room for further improvements in this regard.

Table 2: Breed of bulls used for semen collection purposes in Africa in 1998 (Adapted from Thibier \& Wagner, 2002).

\begin{tabular}{|l|l|l|}
\hline Breed of bull & Number of bulls used & $\begin{array}{l}\text { Expressed as a proportion of the } \\
\text { global pool of bulls used for semen } \\
\text { collection }\end{array}$ \\
\hline Dairy breeds (Bos taurus) & 553 & $1.83 \%$ \\
Beef breeds (Bos taurus) & 45 & $0.64 \%$ \\
Beef breeds (Bos indicus) & 16 & $2.07 \%$ \\
Dual purpose breeds & 7 & $0.49 \%$ \\
Buffalo & 25 & $4.92 \%$ \\
\hline
\end{tabular}

There is a vast amount of literature that confirms the rapid uptake of AI, due to the technical, genetic and economic advantages in the commercial dairy industry in the developed countries around the world (Cunningham, 1999; Corrigan \& Parnell, 2006). In Africa, about $85.6 \%$ of semen produced is also from dairy type bulls, which generally agrees with the trends for semen production elsewhere in the world. The main reason for this trend is that $\mathrm{AI}$ is most practical and has the greatest impact on dairy production systems.

It has been indicated by Pollack (2005) that AI is less used in commercial beef cattle due to the fragmented structure of the beef industry compared to dairy, but it still makes a significant contribution 
with regard to genetic impact. Difficulties associated with the management of an AI program for extensively kept beef cattle and the generally lower success rates of such programs are reasons for the beef industry also being more reluctant to adopt $\mathrm{AI}$ as a reproductive biotechnology. The advent of synchronization of estrus has spurred new interest in the use of AI in extensive beef herds, and such programs appear to be much more lucrative. In South Africa, the use of AI in beef cattle is most popular in stud cattle breeding, although AI is used on a limited scale in three-way crossbreeding systems to improve the management of the breeding program. Smaller cattle operations often used AI in two-way crossbreeding systems due to the unavailability of good quality bulls at an affordable price. Despite these well documented advantages of a relative simple technique African livestock farmers still face a number of limitations for successful implementation of AI. Several factors are discussed in literature ranging from a lack of infrastructure and animal recording systems (Cunningham, 1999; Kahi \& Rege, 2008; Rege et al. 2011; Mirkena et al. 2010) to cost of the technology, clear breeding objectives and insufficient capacity to adapt to continuously changing production systems and markets.

In small stock production systems in Africa, the purpose of AI is focused more on the exploitation of specific sires in a breeding flock, because a single ram can only impregnate 30 to 40 ewes with ease during the breeding season. A single ejaculate from such a ram can be diluted and used to impregnate 100 or more ewes. Ewes are thus synchronized by means of vaginal sponges containing progesterone and are inseminated with fresh-diluted semen from a sought after ram on the farm. Similar methodologies are employed in goats, especially in dairy goats where milk production has to be managed over a 12 -month period. Synchronization of estrus of ewe or does plays an important part in the management of such breeding programs. In both sheep and goats, these technologies are also employed as part of accelerated breeding programs, by including flushing (flush feeding) with specific nutrients to increase twinning and improve conception rates.

Artificial insemination is primarily practiced in intensive pig production systems and seed stock operations. The technique is easy to learn and the conception rates in such systems are high. In an African 
context South Africa is the major producer of pork. In a number of other African countries, pigs as a species face several challenges with regard to the intensive nature of production as well as religious and social constraints.

\section{Animal recording systems: a prerequisite for successful reproductive biotechnology}

Animal recording is a probably the most important tool or technology in the long process of genetic improvement of livestock. Recording begins with the identification of the animal and may then vary from a simple recording system consisting of pedigrees, calving dates and number of offspring to complex recording of all possible fitness, production, quality and behavioural traits (Peters \& Zumbach, 2004). Reproductive biotechnology as a technique may be simple enough to implement, but without a recording system it is unlikely that it will have the desired intended effect on genetic improvement.

In general, in African countries there is a lack of animal identification systems and pedigree and or performance recording. In countries such as Ethiopia and Kenya centralized programs were implemented for small stock (sheep and goats) improvement with varying degrees of success. Different approaches have been suggested for genetic improvement in tropical regions such as within breed selection and or cross breeding. In the case of within breed selection artificial insemination is an option for producing offspring of improved quality for the desired traits. In Kenya within breed selection failed largely due to the absence of animal identification and performance and pedigree recording systems (Kosgey et al. 2006). In addition to these basic requirements for genetic improvement there are other constraints such as small flock sizes, single sire flocks and pastoralist systems, low level if literacy and cultural values. In several papers nucleus schemes have been recommended for genetic improvement in developing countries (Kosgey et al, 2006). Nucleus schemes have the advantage of all recording and selection to be done within the nucleus herds or flocks. This provides more opportunity for effective application of reproductive biotechnologies. The best animals are kept within the nucleus and selected for the desired 
traits from where good quality animals can be provided to the smallholder farmers who do not have the infrastructure or support to perform detailed animal recording. In this system native breeds can be used effectively without indiscriminate use of crossbreeding. In many of the African countries centralized programs were initiated, but failed on the long term due to the absence of technical support and participation (Rege et al. 2011).

Kenya had a recording scheme for beef and dairy cattle since 1963 that was supported by government with regard to animal health, AI schemes, tick control and livestock extension training (Kosgey et al. 2011). Since 1992, several organizations have been responsible for animal recording in Kenya providing the services for registration of stud animals (KSB, Kenya Studbook) and a milk recording (Dairy recording services of Kenya). The cattle and dairy breed societies and their breeders form part of the Kenyan Livestock Breeders Organization (KLBO) and record information is provided to the Livestock Recording Centre (LRC) with links to a central AI Station (CAIS). Despite a well-designed structure Kosgey et al. (2011) notes that participation remains low as breeders fail to see the benefits of the recording scheme. Even among Boran breeders taking part in the recording scheme, pedigree information for both dams and sires are often incomplete. Kios et al. (2011) found that misidentification of sires varied between $4.3 \%$ and $80 \%$ in a study where DNA markers were applied to test for parentage in four Boran stud herds. The integration of the different structures with regard to AI services and recording is not at a level that promotes the potential genetic improvement that can be realized from these systems. Cattle and dairy breeders in Kenya have access to recording and the use thereof has had certain benefits. Boran breeders for example use reproductive technology and also export embryos to Southern Africa (http//www.embryoplus.com). Small holder dairy farmers in Kenya do use AI, although on a small scale (Bebe et al. 2003). There may be constraints and challenges to overcome but in Kenya a recording system is in place with potential for using reproductive technology and producing animals of high genetic merit for improved production. 
In South Africa and Namibia animal recording systems have been successfully implemented making genetic evaluations of a number of cattle and small stock breeds possible. Estimated Breeding Values (EBV's) are calculated and applied in selection programs in combination with reproductive technologies (AI, Embryo Transfer). National performance schemes have been established in South Africa for dairy (1917), beef (1959) and small stock (1965) (Bergh, 2010), where these schemes formed an integral part of the genetic improvement of livestock breeds in this country. Most breeds are involved in performance recording at least with regard to data collection for reproduction and weaning weight. Since the midnineties BREEDPLAN has also been available for stud breeders in South Africa and Namibia. In 2011 SA Studbook has extended their services for production recording and genetic evaluations for all livestock species. In Botswana a most effective system is used namely the "Livestock Identification and Trace-back system" (LITS) that is based on a reticular bolus containing a microchip in the middle. Animals can be traced at all times and extension officers can collect information at a herd level. The majority of beef produced in Botswana is exported to European countries where the EU regulations (EU 1760/2000) require traceability from all animals (Department of Animal Health and Production, Botswana, 2000).

\section{Managing reproduction within a resource limiting environment}

Different technologies are used in Africa to manage reproduction in livestock, most of which are based on improving conception rates, decreasing inter-calving periods and reducing postpartum anoestrus. Some of these principles are based on indigenous knowledge, but African farmers have also adopted new reproductive biotechnologies and management methods. One of the major challenges is to manage livestock production in a resource limited environment, which requires careful synchronisation of the production level of livestock with the production potential of the environment, based on the most limiting climatological factors. 
Environmental temperature and humidity, annual precipitation, quality and quantity of natural feed resources and endo-and ectoparasites are the most limiting environmental constraints for livestock production in Africa. Environmental temperature and humidity have major effects on reproduction of livestock and these effects are well documented. Bonsma's classic work on heat tolerance showed that non-adapted cattle breeds in the sub-tropics demonstrate severely stunted growth and reproductive development (Bonsma, 1980). This condition was referred to as tropical degeneration and it is wellknown that heifers of the British beef breeds in Africa often have infantile reproductive systems at breeding age. Crossbreeding with indigenous cattle breeds was recommended to improve beef production in arid regions.

In Friesland bulls at an AI-centre in South Africa, better sperm morphology was observed in spring and winter than in summer and autumn (Vilakazi \& Webb, 2004). Percentage normal sperm decreased and major sperm defects increased with increasing environmental temperature. It was recommended that semen collection in Friesland bulls should be done at 36 to 48 months of age and preferably during spring or winter, to ensure best semen quality. Friesland bulls kept for semen collection at AI-centres in South Africa are often kept in cool and dry conditions and in some instances the bulls are sprayed and cooled down with fans to ensure good quality semen.

There are many examples of reproductive failure or poor reproduction due to nutrient deficiencies. Energy and protein content are the major nutritional causes of poor reproduction, especially in a resource limited environments. The maintenance of body energy reserves is considered to be the basis of any reproductive management strategy (Houghton et al. 1990; Morrison et al. 1999; Flores et al. 2008). It is well known that the Gonadotropin releasing hormone $(\mathrm{GnRH})$ pulse generator system and subsequent secretion of $\mathrm{GnRH}$ from the hypothalamus are inhibited by under nutrition. Protein and energy supplementation have been an effective strategy to improve reproductive performance of livestock in Africa. 
Protein supplementation in feeds is quite costly in modern beef and small stock production systems in South Africa, so supplementation is only beneficial if there are improvements in terms of production and reproductive rates. Dietary manipulation of reproduction has been investigated in small stock by focussing on the effects of high protein intake. The effects of different protein sources on ovulation rates were also studied in sheep (Webb et al. 2010) based on the concept of a lower level of protein degradation in the rumen and subsequent availability of protein in the lower digestive system. The results indicate that dietary protein supplementation in ewes has a positive effect on follicle development, but only a marginal effect on the number of lambs born per ewe mated (Webb et al. 2010).

In the early 1900's poor reproduction in cattle in southern Africa was linked to aphosphorosis in phosphorus deficient grazing (Theiler, Green \& Du Toit, 1927). Large parts of South Africa, especially the grassland areas are considered phosphorus-deficient (Du Toit, Louw \& Malan, 1940). Phosphorus supplementation of cattle in the form of salt-phosphate licks remedied this problem and this legendary strategy is now widely used for cattle production (Read \& Engels, 1986). Supplementary feeding has become an accepted practice in livestock production and a large proportion of this is based on salt licks with molasses and urea or other sources of non-protein nitrogen. In addition to calcium and phosphorus, a variety of other macro- and micro-minerals and vitamins are also supplemented to improve reproductive rate. Flush-feeding is a popular practice in small-stock production systems in South Africa. The energy levels of the diet is increased resulting in higher ovulation and conception rates. Although this technique is used in cattle, it is less effective and therefore less popular.

Reproductive efficiency of postpartum dairy and beef cows has been improved by careful management of body condition and energy balance at parturition. Body condition scores exceeding 2.5(scale 1-5) and an increasing energy balance at the beginning of the breeding season improved conception rates from $60 \%$ to as high as $90.5 \%$ in extensively kept Brahman-type cows in Moçambique (Escrivao et al. 2012). It is not 
exactly clear how suckling extends postpartum anoestrus in cattle, but suckling frequency correlates best with the duration and extent of postpartum anoestrus (Stewart et al. 1993). Results show that temporary calf separation at night improved the energy balance and conception rates of postpartum cows without adversely affecting calf-weaning weights (Escrivao et al. 2009). Temporary calf separation has long been practiced by African herdsmen to protect their calves from predators, but it is uncertain if they appreciated the benefits of this practice in terms of improvements in reproductive efficiency.

In some countries there is a preference for increased frame size in cattle due to the favourable correlation with growth rate (Du Plessis et al. 2005), but such animals are not favoured in extensive systems in Africa where grazing quality is frequently poor. Frame size significantly influences reproductive efficiency of beef cows in Africa. A study in Namibia found that calving rate was higher in small and medium frame cows compared to large frame cows (Taylor et al. 2008). Weaning rates of large frame cows were less than those of small and medium frame cows, although weaning weights of calves were higher for large and medium frame cows. Moreover, the total kilograms of calf produced per cow bred were higher for medium and small frame cows compared to large frame cows.

Breeding seasons is another strategy employed in sedentary African livestock production systems to combat the negative effects of extreme environmental temperatures and humidity. The use of breeding seasons allows the opportunity to breed cows in spring or early summer, so that cows calve down when the quality of the grazing starts to improve. This strategy has been employed for decades in the subtropical parts of Africa with great success. Breeding seasons are not used in nomadic livestock production systems, as in these systems the cattle are continuously moved in search of better grazing, which negates the use of breeding seasons. In intensive or semi-intensive dairy production, the 'temperature-humidity Index' (THI) was developed to manage dairy cows in hot and humid environments (Du Preez et al.1991). THI correlated significantly with conception rates in dairy cows in South Africa 
and this system provides an accurate index to calculate the risk of dairy cows for thermal stress during hot summer months.

An overall breeding soundness examination (OBE) is a quick, reliable and cost- effective method of screening and classifying bulls in terms of breeding potential (Ellis et al. 2005). The latter as well as fertility tests before the onset of the breeding season contribute significantly towards better conception rates in beef herds. However, reproductive (semen quality) and growth data does not appear to be reliable predictors of libido in extensively managed bulls (Scheepers et al. 2010). Scrotal circumference is used more effectively to select beef bulls for fertility and semen production potential.

\section{Reproductive technology and the impact on food production?}

The aim of reproductive biotechnologies is to accelerate genetic gain with greater selection pressure on the males (AI) and females (ET). The point of departure for the effective implementation of these technologies is some form of animal identification and performance recording. From the literature reviewed here and elsewhere in World Bank and FAO reports, it is clear that Africa needs to overcome a number of obstacles before individual farmers and countries my reap the genetic and production benefits of reproductive technologies. The solutions to the limitations facing farmers, livestock owners and governments are unfortunately not all of a scientific nature. Some major drivers of change according to Rege et al. (2011) include population growth, urbanization and changes in food preferences; climate change that may lead to more frequent drought or flooding with a direct influence on available grazing and water for livestock and crops. Furthermore, Africa has little choice to become part of the global village and this may be seen as a threat or an opportunity to be able to produce for both local and international markets. 
Apart from the non-genetic challenges that are beyond the scope of this discussion it may be time for Africa to adapt the available technology to suit the needs of African livestock producers. As Machuka (2001) so rightfully stated with regard to biotechnology in crop production: "Biotechnology for Africa should mostly be done in Africa and by African themselves now. It can be done if there is consensus and goodwill”.

There is a good consensus with regard to livestock breeds for Africa among scientists and clearly a need for understanding the role of adapted genotypes for different environments and production systems. The livestock production challenges of small holders and pastoralists need to be addressed with regard to adapted breeds although production may be lower compared to exotic breeds. For small holders and communal farmers and pastoralists, alternative practices for performance recording should be considered. Identification should be a relative simple procedure such as ear notching. In the absence of scales, alternatives measures for weight such as girth depth, chest depth and body length could be considered (Alderson, 1999). Despite potential human error in using linear measurements, it can be used by the small holder farmer to establish norms. Animal recording should be combined with management practices where farmers can see the benefits on a short term basis. New and innovative tools for recording by using hand held electronic data capturing systems could be considered with support from livestock officers and farmers cooperatives to collect and store data of identified animals.

Reproductive technology will find application within structures, private or via research institutions from where the improved genetics may be distributed to small holders keeping in mind that the genotype will fit the system. In countries such as Kenya, Zimbabwe, Zambia Botswana, Namibia and South Africa animal recording and reproductive technologies had made an impact and it is expected that it will expand in these countries and across their borders. In some countries exotic breeds may be the obvious choice for intensive and semi-intensive production systems as successfully done in South Africa. 
Animal scientists and agricultural policy makers should be aware of the diversity of climatic regions and production systems to ensure sustainability. Rege et al. (2011) suggested different breed options for different production systems ranging from pastoral systems using mostly indigenous breeds, mixed systems in semi-arid/semi humid regions using indigenous with some crossbreds to highland regions where $50 \%$ exotic breeds can be used in crossbreeding as well as pure bred dairy cattle. In both the mixed and highland regions biotechnology such as AI may find application with an expected medium to high impact. In smallholder systems in East Africa it is more likely that crossbreds will be used in cattle and goats with the development of composite breeds.

Strategies for increasing livestock production in Africa using any form of biotechnology needs careful planning and due consideration of the available indigenous livestock species (cattle, sheep, goats and poultry), indigenous knowledge and production systems.

\section{Conclusion}

Reproductive technology is an important tool for accelerating genetic progress through both AI and ET. For reproductive technology to be effective it is of the utmost importance that breeding objectives will be well defined with regard to the breed choice and the specific traits with due consideration of the environmental challenges, production system and the use of some form of animal recording. In Africa reproductive technology generally had limited success, except for a few countries where animal recording schemes have been in place for a number of decades. The technology is available and Africa has a sufficient number of livestock breeds to comply with the increasing demand for proteins from animal origin. There is a need for improved management of non- genetic interventions for biotechnology to succeed on the African continent and contribute substantially to food production and security.

\section{References}

Alderson GLH. The development of a system of linear measurements to provide an assessment of type and function of beef cattle Animal Genetic Resources, 1999;25:45-55 
Amare B, Kefyalew A, Zeleke. Typical features, characterization and breeding objectves of Begait sheep in Ethiopia Animal Genetic Resources, 2012;50:1-7

Baker RL. Genetic resistance to endoparasites in sheep and goats A Review of genetic resistance to gastrointestinal nematode parasites in sheep and goats in the tropics and evidence for resistance in some sheep and goat breeds in sub-humid coastal Kenya Animal Genetics Resources 1988;24:13-30.

Bebe BO, Udo HMJ, Rowlands GJ, Thorpe W. Small holder dairy systems in the Kenay highlands: breed preferences and breeding practices Livestock Production Science. 2003;82:117-127.

Bergh L. The National beef recording and improvement scheme Ch 5 In "Beef breeding in South Africa" edited by MM Scholtz Agricultural Research Council www. Agric.za. 2010.

Bonsma JC. Livestock production: A global approach, Tafelberg. 1980.

Corrigan L, Parnell PF. Application of genetics technology in the temperate Australian beef seedstock industry Proceedings of Australian Beef - The Leader! Conference, University of New England, Armidale, 7-8 March 2006.

Cunningham EP. The application of biotechnologies to enhance animal production in different farming systems Livestock Production Science. 1999;58:1-24.

Delgado C, Rosengrat M, Steinfeld H, Ehui S, Courbis C. Livestock 2020: the next food revolution, food, agriculture and the Environment discussion paper 28 IFPRI/FAO/ILRI, IFPRI, Washington DC, USA. 1999.

Department of Animal Health and Production, Botswana. Omang Wa Dikgomo. Livestock identification and Trace-back system Department of Veterinary Services, Private Bag 0032, Gabarone, Botswana. 2000.

Du Preez JH, Terblanche SJ, Giesecke WH, Maree C, Welding MC. Effect of heat stress on a dairy herd model under South African conditions, Theriogenology. 1991;35(5):1039-1049. 
Du Toit PJ, Louw JA, Malan AI. A study of the mineral content and feeding value of natural pastures in ther Union of South Africa, Onderstepoort J Vet Res. 1940;14:123.

Du Plessis I, Hoffman LC, Calitz FJ. Influence of reproduction traits and pre-weaning growth rate on herd efficiency of different beef breed types in an arid sub-tropical environment, S Afr J Animal Science Vol 35. 2005;89-98.

Ellis RW, Rupp GP, Chenoweth PJ, Cundiff LV, Lunstra DD. Fertility of yearling beef bulls during mating Theriogenology. 2005;64:657-678.

Escrivao RJA, Webb EC, Garces APJT. Effects of 12 hour calf withdrawal on conception rate and calf performance of Bos indicus cattle under extensive conditions, Tropical Animal Health Production. 2009;41:135-139.

Escrivao RJA, Webb EC, Garces APJT, Grimbeek RJ. Effects of 48 hour calf withdrawal on conception rates of Bos indicus cows and calf weaning weights in extensive production systems, Tropical Animal Health Production. 2012;44:1779-1782.

Faustin PL, Kyvsgaard NC. Improving pig husbandry in tropical resource-poor communities and its potential to reduce risk of porcine cysticercosis Acta Tropica. 2003;87:111-117.

Flores R, Looper ML, Rorie RW, Hallford DM, Rosenkrans CF Jr. Endocrine factors and ovarian follicles are influenced by body condition and somatotropin in postpartum beef cows, Journal of Animal Science. 2008;86:1335-1344.

Gizaw S, Van Arendonk JAM, Komen H, Windig JJ, Hanotte O. Population structure, genetic variation and morphological diversity in indigenous sheep of Ethiopia Animal Genetics. 2007; 38:621-628. 
Goosens B, Osaer S, Ndao M, Van Winghem J, Geerts. The susceptibility of Djanllonke and DkallonkeSahelian crossbred sheep tp Trypanosoma congolense and helminth infection under different diet level Veterinary Parasitology. 1999;85(1):25-41.

Hanotte O, Jianlin H. Genetic characterization of livestock populations and its use in conservation decision-making. The Role of Biotechology, Villa Gualino, Italy 5-7 March 2005.

Holt W, Pickard AR. Role of reproductive technologies and genetic resource banks in animal conservation, Reviews of Reproduction. 1999;4:143-150.

Houghton PL, Lemeneger RP, Moss GE, Hendrix KS. Prediction of Postpartum Beef Cow Body Composition Using Weight to Height Ratio and Visual Body Condition Score, Journal of Animal Science. $1990 ; 1428-1437$.

Ibeagha-Awemu EM, Erhardt G. Genetic structure and differentiation of 12 African Bos Indicus and Bos Taurus cattle breeds, inferred from protein and microsatellite polymorphisms Journal of Animal Breeding Genetics. 2004;122:12-20.

Kahi AK, Rewe TO. Biotechnology in livestock production: Overview of possibilities for Africa African Journal of Biotechnology Vol 7. 2008;25:4984-4991.

Kios D, Van Marle-Köster E, Visser C. Application of DNA markers in parentage verification of Boran cattle in Kenya Tropical Animal Health and Production. 2011; 41: No3:

Koehler-Rollefson I. Sustainable solutions need smallholder systems Global Donor Platform for Rural Development http://wwwdonorplatformorg/livestock-and-pastoralism. 2012.

Kosgey IS, Baker RL, Udo HMJ, Van Arendonk JAM. Successes and failures of small ruminant breeding programmes in the tropics: a review Small Ruminant Research. 2006;61:13-28. 
Kosgey IS, Mbuki SM, Okeyo AM, Amimo J, Philipsosson J, Ojango JM. Institutional and organizational frameworks for dairy and beef cattle recording in Kenya: a review and opportunities for improvement Animal Genetic Resources. 2011;48:1-11.

Lenstra JA, Groeneveld LF, Eding H, Kantanen J, Williams JL, Taberlet P, et al. Molecular tools and analytical approaches for the characterization of farm animal genetic diversity. Animal Genetics. $2011 ; 41: 1-20$

Machuka J. Agricultural Biotechnology for Africa African Scientists and Farmers must feed their own people Plant Physiology Vol 126. 2001;16-19.

Mapiye C, Chimomyo M, Muchenje V, Dzama K, Mumyaradzi CM, Raats JG. Potential for value addition of Nguni cattle products in the communal areas of South Africa: a review African Journal of Agricultural Research Vol 2. 2007;10:488-495.

Mattiolo RC, Pandey VS, Murray M, Fitzpatrick JL. Immunogenetic influences on tick resistance in African cattle with particular reference to trypanotolerant N'Dama (Bos taurus) and trypanosusceptible Gobra zebu (Bos indicus) cattle Acta Tropical 31 May 2000;75(3):263-77.

Mirkena T, Duguma G, Haile A, Tibbo M, Okeyo AM, Wurzinger M, Solkner J. Genetics of adaptation in domestic farm animals: A review Livestock Science. 2010;132:1-12.

Morrison DG, Spitzer JC, Perkins JL. Influence of prepartum body condition score change on reproduction in multiparous beef cows calving in moderate body condition score, Journal of Animal Science. 1999;1048-1053.

Mwacharo, JM, Okeyo, AM, Kamande, GK \& Rege, JEO. The small East African shorthorn zebu cows in Kenya.I: Linear body measurements. Tropical Animal Health Production. 2006;38:65-74. 
Peters KJ, Zumbach B. Needs for research and development in Livestock recording Systems( LRS) in transition and developing countriesTechnical series no 9, Development of animal identification and recording systems for the developing countries, edited by R Pauw, S Mack \& Maki-Hokkonen. 2004;152174.

Pica-Ciamarra U, Baker D, Bedane B, Emwanu T, Morgan N. Intergrating Livestock into Agricultural Statistics Joint paper of the World Bank, FAO October 2010.

Pollak EJ. Application and impact of new genetic technologies on beef cattle breeding: a "real world perspective" Australian Journal of Experimental Agriculture. 2005;45:739-748.

Qwabe SO, Van Marle-Köster E, Visser C. Genetic diversity and population structure of the endangered Namaqua Afrikander sheep Tropical Health Production DOI 101007/s 11250-012-0250 online. 2012.

Read MVP, Engels, EAN. Phosphorus and the grazing ruminant 2 The effects of supplementary P on cattle at Glen and Armoedsvlakte, South African Journal Animal Science. 1986;16:7-12.

Rege JEO. The state of African cattle genetic resources I Classification framework and identification of threatened and extinct breeds Animal Genetics Resources. 1999;25:1-25.

Rege JEO, Marshall K, Notenbaert A, Ojango JMK, Okeyo AM. Pro-poor animal improvement and breeding - What can science do? Livestock Science. 2011;136:15-28.

Roberts CJ, Gray AR. Studies on trypanosome-resistant cattle II The effect of trypanosomiasis on N'dama, Muturu and Zebu cattle Tropical Animal Health Production Nov. 1973;5(4):220-33.

Rode LM, McAllister TA, Beauchemin KA, Morgavi DP, Nsereko VL, Yang WZ, Iwaasa AD, Wang Y. Enzymes as direct-feed additives for ruminants In: Biotechnology in Animal Husbandry, Edited by Renaville and Burny Kluwer Academic Publishers. 2010. 
Ruxandra, Draghia-Akli R. Gene therapeutic enhancement of animal health and performances In Biotechnology in Animal Husbandry Edited by Renaville and Burny Kluwer Academic Publishers. 2010.

Scheepers SM, Annandale CH, Webb EC. Relationship between production characteristics and breeding potential of 25-month old extensively managed Bonsmara bulls, South African Journal Animal Science. 2010;40(3):163-173.

Scherf BD. World Watch list for domestic animal diversity $3^{\text {rd }}$ Edition Edited by B D Scherf FAO UNEP. 2000.

Spickett AM, De Klerk D, Enslin CB, Scholtz MM. Resistance of Nguni, Bonsmara and Hereford cattle to ticks in a Bushveld region of South Africa Onderstepoort Journal of Veterinary research. 1989;56 : 245-250.

Stewart IB, Louw BP, Lishman AW. Suckling behaviour and fertility in beef cows on pasture, 1 Suckling behaviour S Afri Journal of Animal Science. 1993;23:176-179.

Scholtz MM, McManus C, Okeyo AM, Theunissen A. Opportunities for beef production in developing countries of the southern hemisphere Livestock Science. 2011;142:195-202.

Taberlet P, Valentini H, Rezaei R, Naderi S, Pompanon F, Negrini R. Are cattle, sheep and goats endangered species? Molecular Ecology. 2008;17:275-284.

Taylor G, Swanepoel FJC, Webb EC, Stroebel A. Effect of heifer frame size on their subsequent reproductive performance and preweaning performance of their calves, Australian Journal of Experimental Agriculture. 2008;48:945-949.

Theiler A, Green HH, Du Toit PJ. Minimum mineral requirements in cattle, Journal of Agricultural Science. 1927;17(3):291-314. 
Thibier M, Wagner H-G. World statistics for artificial insemination in cattle, Livestock Production Science. 2002;74:203-212.

Thornton PK. Livestock production: recent trends, future prospects Philosophical Transactions of The Royal Society. 2010;365:2853-2867.

Van Arendonk JAM. The role of reproductive technologies in breeding schemes for livestock populations in developing countries Livestock Science. 2011;136:29-37.

Vilakazi DM, Webb EC. Effect of age and season on sperm morphology of Friesland bulls at an artificial insemination centre in South Africa, South African Journal Animal Science. 2004;34(1):62-69.

Webb EC, Van Niekerk WA, Lee K, Marais WJ. Reproductive performance of semi-extensively kept Döhne Merino ewes fed with different protein sources, South African Journal Animal Science. 2010;40,5(1):451-454. 